\title{
Article \\ Handgrip Strength: Associations with Clinical Variables, Body Composition, and Bone Mineral Density in Adults with Cystic Fibrosis
}

\author{
Victoria Contreras-Bolívar ${ }^{1,2}$, Casilda Olveira ${ }^{3,+}\left(\mathbb{D}\right.$, Ignacio Ruiz-García ${ }^{1} \oplus$, Nuria Porras ${ }^{1}$, \\ Maria García-Olivares ${ }^{1}$ (D), Francisco José Sánchez-Torralvo ${ }^{1}$ (D), Maria Victoria Girón ${ }^{3}$, \\ Silvia P. Alonso-Gallardo ${ }^{1}$ and Gabriel Olveira ${ }^{1,4, *,+}$ (D)
}

check for updates

Citation: Contreras-Bolívar, V.;

Olveira, C.; Ruiz-García, I.; Porras, N.; García-Olivares, M.; SánchezTorralvo, F.J.; Girón, M.V.; Alonso-Gallardo, S.P.; Olveira, G. Handgrip Strength: Associations with Clinical Variables, Body Composition, and Bone Mineral Density in Adults with Cystic Fibrosis. Nutrients 2021, 13, 4107. https://doi.org/10.3390/ nu13114107

Academic Editor: Yoshiyuki Morishita

Received: 1 November 2021 Accepted: 13 November 2021 Published: 16 November 2021

Publisher's Note: MDPI stays neutral with regard to jurisdictional claims in published maps and institutional affiliations.

Copyright: (c) 2021 by the authors. Licensee MDPI, Basel, Switzerland. This article is an open access article distributed under the terms and conditions of the Creative Commons Attribution (CC BY) license (https:// creativecommons.org/licenses/by/ $4.0 /)$.
1 Servicio de Endocrinología y Nutrición, Hospital Regional Universitario de Málaga, Instituto de Investigación Biomédica de Málaga (IBIMA), Universidad de Málaga, 29010 Málaga, Spain; victoriaconbol@gmail.com (V.C.-B.); nach1991@gmail.com (I.R.-G.); nporrasperez@hotmail.com (N.P.); mery.garcia.96@gmail.com (M.G.-O.); fjstsol@gmail.com (F.J.S.-T.); silvia_94_86@hotmail.com (S.P.A.-G.)

2 Servicio de Endocrinología y Nutrición, Hospital Universitario Clínico San Cecilio, Instituto de Investigación Biosanitaria (Ibs, Granada), 18016 Granada, Spain

3 Servicio de Neumología, Hospital Regional Universitario de Málaga, Instituto de Investigación Biomédica de Málaga (IBIMA), Universidad de Málaga, 29010 Málaga, Spain; casi1547@separ.es (C.O.); marivi_giron@hotmail.com (M.V.G.)

4 Centro de Investigación Biomédica en Red-Diabetes y Enfermedades Metabólicas Asociadas (CIBERDEM), 08036 Barcelona, Spain

* Correspondence: gabrielm.olveira.sspa@juntadeandalucia.es

+ These authors contributed equally to this work.

Abstract: Background: Loss of fat-free mass (FFM) is associated with an increase in morbidity and mortality in cystic fibrosis (CF) patients. Handgrip strength (HGS) measures muscle function and may be associated with clinical parameters with prognostic value. Our objectives were to evaluate muscle strength through HGS in CF patients and to determine if there are any associations with respiratory clinical variables, FFM, and bone mineral density (BMD). Methods: A cross-sectional study conducted in clinically stable patients. We evaluated muscle function through HGS, respiratory function-forced expiratory volume in $1 \mathrm{~s}$ (FEV1) (\%), forced vital capacity (FVC) (\%), bronchorrhea, annual exacerbations, and body composition (FFM and FFM index, FFMI: fat-free mass in $\mathrm{kg} / \mathrm{height}$ in $\mathrm{m}^{2}$ ) and Bone Mineral Density (BMD) through densitometry (DXA). Results: The study included 53 CF patients (58.5\% females, mean age $28.3 \pm 8.1$, body mass index (BMI) $21.7 \pm 3.4$ ). The mean values for dynamometry were $40.2 \pm 8.1 \mathrm{~kg}$ in males and $23.1 \pm 7.0 \mathrm{~kg}$ in women, being $20.8 \%$ below the 10th percentile. Patients with lower muscle strength showed significantly more exacerbations and lower FEV1\% and FVC\%, as well as lower BMI, worse BMD $\left(\mathrm{g} / \mathrm{cm}^{2}\right)$, T-score, and Z-score. A significant and positive correlation was found between the mean and maximum dynamometry values and age, FVC\%, BMI, FFMI, FFM (kg), and BMD. Conclusions: For adults with CF, HGS is a practical tool for assessment of health status. Low values reflect poor nutritional status and are associated with poor respiratory function, low fat-free mass and low bone mineral density.

Keywords: cystic fibrosis; handgrip strength; Jamar handgrip dynamometry; malnutrition; nutritional assessment

\section{Introduction}

Cystic fibrosis (CF) is a multisystem disease caused by the alteration of a unique gene located on chromosome 7 (CFTR, cystic fibrosis transmembrane conductance regulator gene). Malnutrition behaves as a risk factor predictor of morbidity and mortality [1]. Until a few years ago, CF was considered to be associated with malnutrition because it was practically always present at the time of diagnosis and the vast majority of patients 
suffered a deterioration of their nutritional status and died very malnourished. Currently, the prevalence of malnutrition has decreased significantly, although figures close to $25 \%$ continue to be reported in both children and adults [2]. Malnutrition is associated with a decrease in muscle mass, which translates to impaired functional tests and worse body composition. The multisystem involvement in CF, with progressive clinical impairment, may result in loss of peripheral skeletal muscle mass, a progressive decrease in muscle strength, physical activity limitations, and a reduction in activities of daily living, with deterioration in quality of life [3,4].

Clinical practice $\mathrm{CF}$ guidelines recommend performing a periodic nutritional assessment [1]. At every visit, patient weight, height, body mass index (BMI), and weight loss over time are recorded. Besides BMI, it is also recommended to evaluate body composition through different techniques in order to estimate fat-free mass (FFM) [5]. Handgrip strength (HGS), a measure of muscle function, is used as a surrogate for muscle mass and is an indicator of nutritional status. A low level of muscle strength worsens health status and malnutrition [6] and is strongly associated with other clinically and prognostically important measures [7]. Recently, the Global Leadership Initiative on Malnutrition (GLIM) criteria for diagnosing malnutrition have been published, including within the phenotypical criteria muscle mass reduction through such validated techniques as DXA (Dual-energy x-ray absorptiometry), bioelectrical impedance analysis, computed tomography, or magnetic resonance imaging. However, some of these methods for measuring body composition are often unreliable, expensive, or not clinically feasible. Thus, the consensus also considers the use of other functional methods such as HGS [8]. HGS is a validated tool used to evaluate muscle function in different populations, including CF patients [9-15]. Legroux-Gérota et al. associated HGS in adults with bone mineral density (BMD) [10]; likewise, Rovedder et al. (in young adults) [11], Bouma, et al. (in adolescents) [13], and Wells et al. (in children) [14] associated it with respiratory function. Notwithstanding the above, studies evaluating muscle strength through HGS and its association with clinical variables with prognostic value are scarce, especially in adults with $C F$.

Here, our hypothesis is that HGS is a useful tool for nutritional assessment of FFM and that it is associated with parameters of clinical severity.

The objective of our study is to evaluate muscle strength through HGS in clinically stable adults with CF and to determinate if it is associated with the clinical variables of respiratory function, body composition and BMD.

\section{Material and Methods}

A cross-sectional observational study with sequential recruitment of patients who attended the CF outpatient consulting room for their annual examination was conducted between January 2016 and January 2017. The inclusion criteria were: (a) regular follow-up with periodic check-ups at the Cystic Fibrosis Unit of the Regional University Hospital of Malaga and attendance for the annual study at the time of data collection; (b) presentation of diagnostic criteria for $\mathrm{CF}$ according to the consensus document published by the Cystic Fibrosis Foundation in 1998; (c) age older than 16 years; (d) having completed pubertal development (Tanner stage V); (e) maintaining a stable clinical condition for at least one month prior to inclusion in the study (no hospital admissions, no respiratory exacerbations requiring intravenous antibiotic therapy and no weight change $>3 \%$ of body weight); (f) to understand the purpose of the study and sign the informed consent form. All patients who met the inclusion criteria were included in the present study.

\subsection{Anthropometric and Body Composition Parameters}

Weight was assessed through bioimpedance (scale mode, weight function; TANITA MC980MA) and height was obtained by a stadiometer (Holtain limited, Crymuch, UK). With these two values, body mass index (BMI) was calculated.

Dual-energy X-ray absorptiometry (DXA) was performed using a Lunar Prodigy Advance densitometer (General Electric Medical Systems), providing information about 
total body composition (FFM, fat mass, and BMD) and bone mineral density (BMD) at the level of the lumbar spine (L1-L4) expressed in $\mathrm{g} / \mathrm{cm}^{2}$; T-score and Z-score were compared with reference values [16]. The diagnosis of low bone mineral density for chronological age or osteopenia/osteoporosis was established according to World Health Organization (WHO) criteria, National Osteoporosis Foundation (NOF) and International Society for Clinical Densitometry (ISCD) guidelines [17-20]. The software used was EnCore 12.3 (iDXA and Prodigy Advance).

In addition, FFM index (FFMI) was calculated (fat-free mass in $\mathrm{kg} /$ height in $\mathrm{m}^{2}$ ) and the prevalence of malnutrition was determined according to European Society for Clinical Nutrition and Metabolism (ESPEN) criteria. Malnutrition according to FFMI was estimated at values $<15$ (women) or $<17$ (men) $\mathrm{kg} / \mathrm{m}^{2}$ [5].

Muscle strength was assessed using an adult dynamometer (Jamar handgrip dynamometry, Asimow Engineering Co., Los Angeles, CA, USA), and was performed in the non-dominant limb, repeated on three occasions and the mean was recorded. The mean was calculated, and along with the highest value was used to represent HGS. To classify normality, data from the Spanish population were used, establishing the cut-off point at p10 [21]. Data were expressed in absolute figures and compared with the reference population [22].

\subsection{Dietary Questionnarie}

A four-day prospective dietary questionnaire (including one day of the weekend) was fulfilled by all the participants, according to the protocol previously published by our group [23]. The provided data were analysed by means of a computer application designed by our group for this purpose (Dietstat ${ }^{\circledR}$ ), and the food composition tables of Jiménez and Mataix [24,25] and BEDCA [26] were used. Moreover, the information on vitamin K (VK) was substituted by the USDA database [27].

\subsection{Assessment of Respiratory Status}

The exacerbations recorded during the annual examination were assessed, taking into consideration those happening in the year prior to the evaluation. Such exacerbations were classified into mild/moderate or severe (suggestive symptoms that worsen and require hospitalization and/or intravenous antibiotics on an outpatient basis) [28]. Moreover, patients underwent forced spirometry via a JAEGER pneumotachograph (Jaeger Oxycon Pro®Erich Jaeger, Würzberg, Germany), following the Sociedad Española de Neumología y Cirugía Torácica (SEPAR) guidelines and determining the values of forced vital capacity (FVC), forced expiratory volume in $1 \mathrm{~s}$ (FEV1), and the ratio between both (FEV1/FVC). The values were expressed in absolute terms in $\mathrm{ml}$ and as percentages according to a reference population [29]. Bronchorrhea, the amount of sputum produced per day expressed in milliliters, was evaluated according to the estimate of the patient during the three days prior to the visit [28].

\subsection{Statistical Analysis}

The Kolmogorov-Smirnov test was used to examine the normality of the quantitative variables, expressed as the mean \pm standard deviation. The differences between groups were analyzed by variance analysis adjusted for age. Non-parametric tests (Mann-Whitney) were used when the variables did not follow a normal distribution. The qualitative variables were expressed as proportions, and differences between groups were analyzed via the Chi-square test, using Fisher's exact test when necessary. The associations of the variables were evaluated by estimating the Pearson or Spearman correlation coefficient, according to normality. For all calculations, a $p$ probability of less than 0.05 significant for two tails was considered significant. The data analysis was performed with the SPSS 22.0 program (SPSS Inc., Chicago, IL, USA, 2013). 


\subsection{Ethics}

All subjects gave their informed consent for inclusion before they participated in the study. The study was conducted in accordance with the Declaration of Helsinki, and the protocol was approved by the Research Ethics Committee of Malaga Province.

\section{Results}

A total of 53 CF patients were included in the study; 22 (41.5\%) were male and $31(58.5 \%)$ were female. Class I and II mutations for the CFTR gene were the most frequently found; for gene A, class I mutation was found in $15.4 \%$ [8], class II in 78.8\% [30], class III in $1.9 \%$ [1], and class IV in 3.8\% [2], while no class V mutations were found. For the B gene, the distribution of mutations was class I in $41.7 \%$ [20], class II in $39.6 \%$ [19], class III in $2.1 \%$ [1], class IV in $10.4 \%$ [5] and class $\mathrm{V}$ in $6.3 \%$ [3]. The most frequently found mutation was F508del (67.9\%), followed by G542X (7.5\%), N1303K (7.5\%) and R334W $(7.5 \%)$, with the remaining mutations being more infrequent. At the time of the study, none of the participants were on treatment with CFTR modulators. Their mean age was $28.3 \pm 8.1$ years (range 16-67). Exocrine pancreatic insufficiency was present in 75.5\% [31] of the patients. Of all the subjects, $49.1 \%$ presented FFM malnutrition, accounting for $27.8 \%$ of male and $68.4 \%$ of female patients. The prevalence of low muscle strength $(<\mathrm{p} 10)$ was $20.8 \%$ [11]. The general characteristics of the patients are displayed in Table 1.

Table 1. General characteristics and respiratory, nutritional, and bone status.

\begin{tabular}{|c|c|c|c|c|c|}
\hline & & \multirow{2}{*}{$\begin{array}{c}\text { CF } \\
\text { Total } \\
(n=53)\end{array}$} & \multicolumn{2}{|c|}{ CF } & \multirow[b]{2}{*}{$p$} \\
\hline & & & $\begin{array}{c}\text { Dynamometry } \\
(n=42)\end{array}$ & $\begin{array}{c}\text { Dynamometry }<\text { p10 } \\
(n=11)\end{array}$ & \\
\hline Age & $(\mathrm{m} \pm \mathrm{SD})$ & $28.3 \pm 8.1$ & $30.4 \pm 7.6$ & $20.5 \pm 4.6$ & $<0.01$ \\
\hline \multicolumn{6}{|l|}{ Sex } \\
\hline Male & $n(\%)$ & $22(41.5)$ & $17(40.5)$ & $5(45.5)$ & NS \\
\hline Female & & $31(58.5)$ & $25(59.5)$ & $6(54.5)$ & \\
\hline \multicolumn{6}{|l|}{ RESPIRATORY } \\
\hline \multicolumn{6}{|l|}{ STATUS } \\
\hline Bronchorrhea (mL) & $(\mathrm{m} \pm \mathrm{SD})$ & $20.5 \pm 20.2$ & $18.6 \pm 20.4$ & $26.5 \pm 19.2$ & NS \\
\hline Total exacerbations & $(\mathrm{m} \pm \mathrm{SD})$ & $2.3 \pm 1.8$ & $2.0 \pm 1.5$ & $3.6 \pm 2.2$ & $<0.01$ \\
\hline Severe exacerbations & $(\mathrm{m} \pm \mathrm{SD})$ & $0.41 \pm 0.80$ & $0.4 \pm 0.8$ & $0.5 \pm 0.8$ & NS \\
\hline FEV1 $(\%)$ & $(\mathrm{m} \pm \mathrm{SD})$ & $63.3 \pm 25.6$ & $67.5 \pm 25.2$ & $56.6 \pm 21.4$ & $<0.001$ \\
\hline FVC (\%) & $(\mathrm{m} \pm \mathrm{SD})$ & $75.3 \pm 22.0$ & $79.6 \pm 18.2$ & $73.9 \pm 23.0$ & $<0.001$ \\
\hline FEV1/FVC (\%) & $(\mathrm{m} \pm \mathrm{SD})$ & $66.7 \pm 12.0$ & $68.0 \pm 15.7$ & $61.4 \pm 17.8$ & NS \\
\hline \multicolumn{6}{|l|}{ Colonisations } \\
\hline S. Aureus colonisation & $n(\%)$ & $42(79.2)$ & $32(76.2)$ & $10(90.9)$ & NS \\
\hline $\begin{array}{l}\text { H. influenzae } \\
\text { colonisation }\end{array}$ & $n(\%)$ & $23(43.4)$ & $20(47.6)$ & $3(27.3)$ & NS \\
\hline $\begin{array}{l}\text { P. aeruginosa } \\
\text { colonisation }\end{array}$ & $n(\%)$ & $41(77.4)$ & $31(73.8)$ & $10(90.6)$ & NS \\
\hline \multicolumn{6}{|l|}{ DIETARY } \\
\hline \multicolumn{6}{|l|}{ QUESTIONNAIRE } \\
\hline Mean calorie intake & $(\mathrm{m} \pm \mathrm{SD})$ & $3444.0 \pm 750.6$ & $3324.4 \pm 638.0$ & $3683.2 \pm 1000.6$ & NS \\
\hline $\begin{array}{c}\text { Calories } / \mathrm{kg} \text { of body } \\
\text { weight }\end{array}$ & $(\mathrm{m} \pm \mathrm{SD})$ & $47.5 \pm 11.6$ & $45.6 \pm 10.6$ & $54.0 \pm 5.0$ & NS \\
\hline Proteins (\%) & $(\mathrm{m} \pm \mathrm{SD})$ & $16.2 \pm 2.4$ & $16.1 \pm 2.5$ & $16.3 \pm 2.6$ & NS \\
\hline $\begin{array}{c}\text { Proteins } / \mathrm{kg} \text { of body } \\
\text { weight }\end{array}$ & $(\mathrm{m} \pm \mathrm{SD})$ & $1.9 \pm 0.6$ & $1.9 \pm 0.6$ & $2.2 \pm 0.6$ & NS \\
\hline Vitamin A (UI) & $(\mathrm{m} \pm \mathrm{SD})$ & $6202.2 \pm 4445.9$ & $5730.0 \pm 4616.9$ & $7820.9 \pm 3629.5$ & NS \\
\hline Vitamin D (UI) & $(\mathrm{m} \pm \mathrm{SD})$ & $3400.4 \pm 2855.5$ & $2961.1 \pm 2515.1$ & $4906.3 \pm 3620.1$ & NS \\
\hline Vitamin E (mg) & $(\mathrm{m} \pm \mathrm{SD})$ & $269.3 \pm 175.0$ & $261.2 \pm 187.5$ & $297.0 \pm 131.3$ & NS \\
\hline Vitamin K (mcg) & $(\mathrm{m} \pm \mathrm{SD})$ & $1078.5 \pm 1596.7$ & $1160.8 \pm 1755.7$ & $776.7 \pm 778.0$ & NS \\
\hline \multicolumn{6}{|l|}{ BONE STATUS } \\
\hline BMD & $(\mathrm{m} \pm \mathrm{SD})$ & $1.092 \pm 0.237$ & $1.169 \pm 0.255$ & $0.991 \pm 0.097$ & $<0.05$ \\
\hline
\end{tabular}


Table 1. Cont.

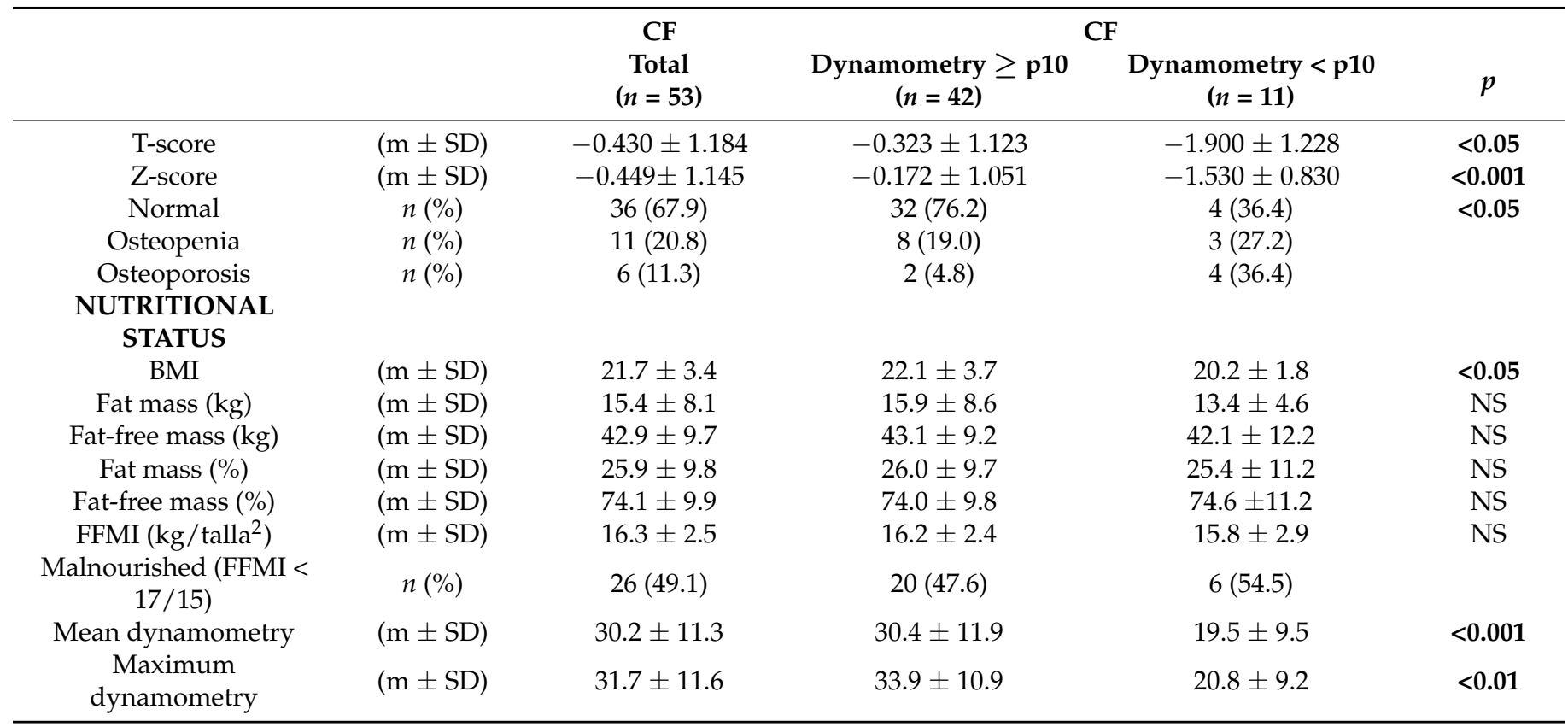

$\mathrm{m} \pm$ SD: mean \pm standard deviation. CF: Cystic Fibrosis. BMD: Bone mineral density BMI: Body mass index. FEV1: Forced expiratory volume in $1 \mathrm{~s}$. FVC: Forced vital capacity. FFMI: Fat-free mass index. FFMI $\geq 17 \mathrm{~V} / 15 \mathrm{M}$ ). Fat-free mass index $\geq 17$ in men and $\geq 15$ in women. $\mathrm{m} \pm$ SD: mean \pm standard deviation. NS: not significant. $p$ : statistical significance for dynamometry between $\geq \mathrm{p} 10$ and $<\mathrm{p} 10$. Bold letters indicating the group names or the significant data.

Separating by groups (dynamometry $\geq$ p10 or $<$ p10), we found that the patients showing lower muscle strength also presented worse respiratory (more total and mild exacerbations, lower FEV1 and FVC), nutritional (lower BMI), and bone status (worse $\mathrm{BMD}, \mathrm{T}$-score, and Z-score), as well as a higher percentage of osteoporosis and osteopenia. We also found a non-significant trend towards more bronchorrhea and chronic $S$ aureus and $\mathrm{P}$ aeruginosa colonisation (Table 1 ). However, we found no significant differences between the two groups on the dietary questionnaire.

Patients with FFM malnutrition measured through DXA (FFMI $<17 \mathrm{~kg} / \mathrm{m}^{2}$ in males and $<15 \mathrm{~kg} / \mathrm{m}^{2}$ in females) presented significantly lower values in HGS compared with normally nourished patients in both mean (35.7 \pm 12.1 vs. $25.1 \pm 6.8 \mathrm{~kg}, p<0.01)$ and maximum $(37.2 \pm 12.3$ vs. $26.6 \pm 6.8 \mathrm{~kg}, p<0.01)$ dynamometry.

Moreover, a positive correlation was found between mean and maximum dynamometry and age, FVC \%, BMI, FFMI $\left(\mathrm{kg} / \mathrm{m}^{2}\right)$, FFM $(\mathrm{kg})$, and BMD (Tables 2 and 3). We found no significance for the dietary questionnaire variables.

Table 2. Correlations between muscle strength and respiratory variables.

\begin{tabular}{ccccccccc}
\hline & Age & Bronchorrhea & $\begin{array}{c}\text { Total } \\
\text { Exacerbations }\end{array}$ & $\begin{array}{c}\text { Mild } \\
\text { Exacerbations }\end{array}$ & $\begin{array}{c}\text { Severe } \\
\text { Exacerbations }\end{array}$ & $\begin{array}{c}\text { FEV1 } \\
\mathbf{( \% )}\end{array}$ & $\begin{array}{c}\text { FVC } \\
\text { (\%) }\end{array}$ & $\begin{array}{c}\text { FEV1/FVC } \\
\mathbf{( \% )}\end{array}$ \\
\hline $\begin{array}{c}\text { Mean } \\
\text { dynamometry } \\
(\mathrm{r})\end{array}$ & 0.334 & 0.051 & -0.067 & -0.024 & -0.110 & 0.222 & 0.302 & 0.042 \\
\hline$p$ & $<0.01$ & $\mathrm{NS}$ & $\mathrm{NS}$ & $\mathrm{NS}$ & $\mathrm{NS}$ & $\mathrm{NS}$ & $<0.05$ & $\mathrm{NS}$ \\
\hline $\begin{array}{c}\text { Maximum } \\
\text { dynamometry } \\
(\mathrm{r})\end{array}$ & 0.312 & 0.072 & -0.117 & -0.074 & -0.135 & 0.232 & 0.331 & 0.057 \\
\hline$p$ & $<0.05$ & $\mathrm{NS}$ & $\mathrm{NS}$ & $\mathrm{NS}$ & $\mathrm{NS}$ & $\mathrm{NS}$ & $<0.05$ & $\mathrm{NS}$ \\
\hline
\end{tabular}

FEV1: Forced expiratory volume in $1 \mathrm{~s}$. FVC: Forced vital capacity. NS: not significant. $p$ : statistical significance. 
Table 3. Correlations between muscle strength and nutritional and bone variables.

\begin{tabular}{cccccccc}
\hline & BMD & T-Score & Z-Score & BMI & FFMI & Fat Mass (kg) & Fat-Free Mass (kg) \\
\hline $\begin{array}{c}\text { Mean dynamometry } \\
(\mathrm{r})\end{array}$ & 0.291 & 0.156 & 0.272 & 0.400 & 0.548 & -0.035 & 0.327 \\
\hline$p$ & $<0.05$ & $\mathrm{NS}$ & $\mathrm{NS}$ & $<0.01$ & $<0.001$ & $\mathrm{NS}$ & $<0.05$ \\
\hline $\begin{array}{c}\text { Maximum } \\
\text { dynamometry } \\
(\mathrm{r})\end{array}$ & 0.289 & 0.120 & 0.246 & 0.388 & 0.676 & -0.039 & 0.331 \\
\hline$p$ & $<0.05$ & $\mathrm{NS}$ & $\mathrm{NS}$ & $<0.01$ & $<0.001$ & $\mathrm{NS}$ & $<0.05$ \\
\hline
\end{tabular}

BMI: Body mass index. FFMI: Fat-free mass index. NS: not significant. $p$ : statistical significance.

\section{Discussion}

In our study, we have found that HGS is associated with respiratory, body composition (FFM), and BMD parameters, making it a useful tool for nutritional and functional assessment in $\mathrm{CF}$ adult patients.

Peripheral muscle dysfunction is an important systemic consequence of CF with major clinical implications including malnutrition, fatigability, reduced physical activity, and reduced quality of life. Furthermore, lack of physical activity, intrinsic CF-related factors, inflammation, and metabolic abnormalities increase with disease severity [32,33].

Muscular strength and function can be measured in CF patients through diverse techniques such as assessing the function of the ventilatory muscles via maximal inspiratory pressure (MIP) and maximal expiratory pressure (MEP), 6- or 12-min walk test, squats, vertical jumping ability, HGS, abdominal strength, arm/shoulder strength, quadriceps muscle strength, and stimulating specific muscles (e.g., the thumb abductor muscle) [15,34]. However, due to its simplicity, easy standardization, and low cost, handgrip dynamometry (HGS) has been proposed as a valid tool for nutritional assessment $[5,8,35]$ as it can perform as a surrogate for muscle mass and an indicator of nutritional and functional status. HGS is associated with prognosis in different clinical populations with increased morbidity and mortality [6,7]. In addition, HGS can be more sensitive to changes in nutritional status than the evaluation of FFM through body composition techniques [36-38].

The prevalence of low muscle strength ( $<10$ th percentile) in our group using HGS was $20.8 \%$. Bouma et al. found an even higher prevalence ( $40 \%$ of individuals aged $6-19$ years) using the same criteria [13].

Rovedder et al. found that HGS was associated with FVC and FEV1 in young adults with CF [11]. In the same way, Bouma et al. reported that in a wide sample population of children, adolescents, and young adults HGS was also positively associated with FEV1\% [13]. Thus, the individuals who were strong for their age (high HGS) were more likely to have a higher FEV1\% than those who were weak for their age; this happened especially in patients with a lower BMI (<50th percentile) [13]. Similarly, in children and adolescents with CF, Sheikh et al. found that FFMI correlated more strongly than BMI to FEV1\% [39]. Wells et al. reported that HGS in children was significantly correlated with respiratory function and peak aerobic capacity (by maximal incremental cycling test) while measures of lower body strength were not; they concluded that simple fitness tests such as HGS may be useful indicators of lung health and fitness [14]. Gibson et al. measured HGS in 23 children with CF during a hospital admission for pulmonary exacerbation, then again six weeks posthospitalization, finding that HGS Z-scores increased significantly after hospitalization. Nevertheless, there was no association between HGS Z-scores and FEV1\%; a small sample size may have affected the results [38]. In our group, patients with lower muscle strength (HGS $<10$ th percentile) had a worse respiratory status, presenting more annual exacerbations and lower values of FEV1\% and FVC\%. Moreover, we found significant positive correlations between $\mathrm{HGS}$ and $\mathrm{FVC} \%$ and a non-significant trend towards more bronchorrhea and chronic $S$ aureus and $P$ aeruginosa colonization [40]. Other authors also reported significant positive associations between other muscle strength 
measures (inspiratory, quads, shoulders) and respiratory function in children and adults with CF $[9,41]$.

In our study, patients with FFM malnutrition had significantly lower HGS values compared with normally nourished subjects. In addition, we found significant positive correlations between mean and maximum dynamometry and BMI, FFMI, and FFM (kg). Other authors also report significant positive correlations between other muscle strength measurements and FFM in children and adults with $\mathrm{CF}[9,13]$. Patients with $\mathrm{CF}$ who are weak for their size may have less FFM, regardless of their BMI, which could negatively impact their respiratory function [13]. Alvarez et al. also reported that an excess of adiposity in adults with CF, particularly in the form of normal-weight obesity associated with low FFM, was inversely associated with respiratory function. Therefore, it is crucial to promote physical activity and an adequate diet in order to improve muscle mass, and also important to monitor the amount of muscle and its function. As HGS is associated with both FFM and respiratory function, this tool behaves as a simple but adequate indicator for nutritional assessment and patient follow-up. Moreover, being an objective measure, it could help motivate patients to engage in physical activity, which increases BMI by building muscle (and not fat mass), reducing sedentary habits, and favouring a healthy diet tailored to their energy and protein requirements [13]. However, in our work we found no association between GSH and protein and fat-soluble vitamin intake.

FFM and muscle strength, along with BMD are independent factors for the prediction of osteoporosis $[31,36]$. We observed that patients who had an HGS greater than p10 had significantly higher BMD, T-score, and Z-score. We found a higher percentage of patients with osteopenia and osteoporosis in the lower strength group. We also observed significant positive correlations between mean and maximum dynamometry and BMD. Legroux-Gérota et al. also reported that, in a sample population of 55 adults with $\mathrm{CF}$, at the femoral, neck, and total hip BMD values correlated with HGS and the 6-min walk test result. In their group, BMD was low in $78.2 \%$ of adults with $C F$, a figure higher than ours, which was associated with respiratory function, physical function (walking test and HGS), and nutritional status [10]. In addition, Gur et al. observed correlations between BMD and HGS (both at hip and spine level), and FFM, in addition to a high percentage of osteoporosis (27.5\%) and osteopenia (37.5\%) in $40 \mathrm{CF}$ patients with a mean age of 18 years [30]. In patients with non-CF bronchiectasis, we also found that respiratory parameters, body composition, muscle strength, and bone remodelling biomarkers were associated with a lower BMD [42]. Moreover, in an interventional study on patients with non-CF bronchiectasis, the addition of a hyperproteic oral nutritional supplement enriched with $\beta$-Hydroxy- $\beta$-Methylbutyrate for pulmonary rehabilitation improved body composition, BMD, and HGS [43]. These results, in a model of chronic respiratory disease similar to $\mathrm{CF}$, evidence the utility of HGS as a surrogate for body composition associated with parameters relevant for patient follow-up.

As strengths of our study, we highlight the use of the HGS normality values of the Spanish population, as well as the assessment of body composition and bone status through DXA (the gold standard in clinical practice), and of respiratory status through different parameters of prognosis in CF (spirometry, bronchorrhea, colonisation). Nonetheless, there are some limitations: it is a cross-sectional study, which impedes drawing conclusions regarding causality; thus, we can only speculate on different associations. Moreover, it is a single-centre study on a moderate number of participants, which poses a greater challenge to generalising of the results.

\section{Conclusions}

In conclusion, the prevalence of low muscle strength in our study was $20.8 \%$ as measured by HGS, and as this technique was associated with clinically important parameters for CF patient follow-up (respiratory, body composition (FFM), and BMD), we propose handgrip dynamometry as a tool to be implemented for nutritional assessment in patients with CF. It is simple, requires a short period of time, has a low cost, and is easy to stan- 
dardize. New prospective studies are still needed in order to evaluate its association with prognosis in terms of morbidity and mortality.

Author Contributions: G.O. and C.O. equally contributed to the conception and design of the research; G.O., C.O. and V.C.-B. contributed to the design of the research; G.O., C.O., V.C.-B., I.R.-G., N.P., M.G.-O., F.J.S.-T., M.V.G. and S.P.A.-G. contributed to the acquisition and analysis of the data; G.O. and V.C.-B. contributed to the interpretation of the data; and G.O. and V.C.-B. drafted the manuscript. All authors critically revised the manuscript, agree to be fully accountable for ensuring the integrity and accuracy of the work. All authors have read and agreed to the published version of the manuscript.

Funding: V.C.B. is funded by postdoctoral fellowships from the Junta de Andalucía (RH-0141-2020). This work was partially supported by FIMABIS (Fundación Pública Andaluza para la Invesitgación de Málaga en Biomedicina y Salud).

Institutional Review Board Statement: The ethical principles contained in the latest revision of the Declaration of Helsinki and the standards of good clinical practice were applied. Confidentiality was guaranteed (Organic Law on Protection of Personal Data 15/1999), as well as that all the information was only used for the purposes specified in the study. The study was approved by the Provincial Research Ethics Committee of Málaga and all participants gave written, informed consent.

Informed Consent Statement: All participants gave written informed consent.

Conflicts of Interest: The authors declare no conflict of interest.

\section{References}

1. Turck, D.; Braegger, C.P.; Colombo, C.; Declercq, D.; Morton, A.; Pancheva, R.; Robberecht, E.; Stern, M.; Strandvik, B.; Wolfe, S.; et al. ESPEN-ESPGHAN-ECFS guidelines on nutrition care for infants, children, and adults with cystic fibrosis. Clin. Nutr. 2016, 35, 557-577. [CrossRef]

2. Culhane, S.; George, C.; Pearo, B.; Spoede, E. Malnutrition in Cystic Fibrosis. Nutr. Clin. Pr. 2013, 28, 676-683. [CrossRef]

3. Ziegler, B.; Rovedder, P.M.E.; Lukrafka, J.L.; Oliveira, C.L.; Menna-Barreto, S.S.; Dalcin, P.D.T.R. Capacidade submáxima de exercício em pacientes adolescentes e adultos com fibrose cística. J. Bras. Pneumol. 2007, 33, 263-269. [CrossRef]

4. Blau, H.; Mussaffi-Georgy, H.; Fink, G.; Kaye, C.; Szeinberg, A.; Spitzer, S.A.; Yahav, J. Effects of an Intensive 4-Week Summer Camp on Cystic Fibrosis. Chest 2002, 121, 1117-1122. [CrossRef]

5. Cederholm, T.; Bosaeus, I.; Barazzoni, R.; Bauer, J.; Van Gossum, A.; Klek, S.; Muscaritoli, M.; Nyulasi, I.; Ockenga, J.; Schneider, S.; et al. Diagnostic criteria for malnutrition-An ESPEN Consensus Statement. Clin. Nutr. 2015, 34, 335-340. [CrossRef] [PubMed]

6. Jochem, C.; Leitzmann, M.; Volaklis, K.; Aune, D.; Strasser, B. Association Between Muscular Strength and Mortality in Clinical Populations: A Systematic Review and Meta-Analysis. J. Am. Med Dir. Assoc. 2019, 20, 1213-1223. [CrossRef] [PubMed]

7. Bohannon, R.W. Muscle strength: Clinical and prognostic value of hand-grip dynamometry. Curr. Opin. Clin. Nutr. Metab. Care 2015, 18, 465-470. [CrossRef] [PubMed]

8. Cederholm, T.; Jensen, G.; Correia, M.I.T.D.; Gonzalez, M.C.; Fukushima, R.; Higashiguchi, T.; Baptista, G.; Barazzoni, R.; Blaauw, R.; Coats, A.J.; et al. GLIM criteria for the diagnosis of malnutrition-A consensus report from the global clinical nutrition community. J. Cachexia Sarcopenia Muscle 2019, 10, 207-217. [CrossRef] [PubMed]

9. Ionescu, A.A.; Chatham, K.; Davies, C.A.; Nixon, L.S.; Enright, S.; Shale, D.J. Inspiratory Muscle Function and Body Composition in Cystic Fibrosis. Am. J. Respir. Crit. Care Med. 1998, 158, 1271-1276. [CrossRef] [PubMed]

10. Legroux-Gérot, I.; Leroy, S.; Prudhomme, C.; Perez, T.; Flipo, R.M.; Wallaert, B.; Cortet, B. Bone loss in adults with cystic fibrosis: Prevalence, associated factors, and usefulness of biological markers. Jt. Bone Spine 2012, 79, 73-77. [CrossRef]

11. Rovedder, P.M.E.; Borba, G.C.; Anderle, M.; Flores, J.; Ziegler, B.; Barreto, S.S.M.; Dalcin, P.D.T.R. Peripheral muscle strength is associated with lung function and functional capacity in patients with cystic fibrosis. Physiother. Res. Int. 2019, 24, e1771. [CrossRef]

12. DeLion, M.; Braux, J.; Jourdain, M.-L.; Guillaume, C.; Bour, C.; Gangloff, S.; Le Pimpec-Barthes, F.; Sermet-Gaudelus, I.; Jacquot, J.; Velard, F. Overexpression of RANKL in osteoblasts: A possible mechanism of susceptibility to bone disease in cystic fibrosis. J. Pathol. 2016, 240, 50-60. [CrossRef] [PubMed]

13. Ma, M.H.M.; Iwanicki, C.; McCaffery, H.; Nasr, S.Z. The Association of Grip Strength, Body Mass Index, and Lung Function in Youth with Cystic Fibrosis. Nutr. Clin. Pr. 2020, 35, 1110-1118. [CrossRef]

14. Wells, G.D.; Wilkes, D.L.; Schneiderman, J.E.; Thompson, S.; Coates, A.L.; Ratjen, F. Physiological correlates of pulmonary function in children with cystic fibrosis. Pediatr. Pulmonol. 2013, 49, 878-884. [CrossRef]

15. Sahlberg, M.E.; Svantesson, U.; Thomas, E.M.L.M.; Strandvik, B. Muscular Strength and Function in Patients With Cystic Fibrosis. Chest 2005, 127, 1587-1592. [CrossRef]

16. Curiel, M.D.; De La Peña, J.L.C.; Perez, J.H.; Cano, R.P.; Rapado, A.; Martínez, I.R. Study of bone mineral density in lumbar spine and femoral neck in a Spanish population. Osteoporos. Int. 1997, 7, 59-64. [CrossRef] 
17. Cosman, F.; De Beur, S.J.; LeBoff, M.S.; Lewiecki, E.M.; Tanner, B.; Randall, S.; Lindsay, R. Clinician's Guide to Prevention and Treatment of Osteoporosis. Osteoporos. Int. 2014, 25, 2359-2381. [CrossRef] [PubMed]

18. World Health Organization. Assessment of Fracture Risk and Its Application to Screening for Postmenopausal Osteoporosis: Report of a WHO Study Group; World Health Organ Technical Report Series; WHO: Geneva, Switzerland, 1994; Volume 843, pp. 1-129.

19. Kanis JA on behalf of the WSG. WHO Scientific Group on the Assessment of Osteoporosis at Primary Health; WHO Collaborating Centre, University of Sheefield: Sheffield, UK, 2008; pp. 5-7.

20. 2019 ISCD Official Positions-Adults; The International Society For Clinical Densitometry (ISCD): Middletown, CT, USA, 2019.

21. Olveira, G. Manual de Nutricion Clinica y Dietetica, 3rd ed.; Ediciones Díaz de Santos, S.A.: Madrid, Spain, 2016.

22. Torralvo, F.J.S.; Porras, N.; Fernandez, J.A.; Torres, F.G.; Tapia, M.J.; Lima, F.; Soriguer, F.; Gonzalo, M.; Martínez, G.R.; Olveira, G.; et al. Normative reference values for hand grip dynamometry in Spain. Association with lean mass. Nutr. Hosp. 2018, 35, 98-103. [CrossRef]

23. Olveira, G.; Olveira, C.; Casado-Miranda, E.; Padilla, A.; Dorado, A.; Rojo-Martinez, G.; Porras, N.; Garcia-Escobar, E.; Soriguer, F. Markers for the Validation of Reported Dietary Intake in Adults with Cystic Fibrosis. J. Am. Diet. Assoc. 2009, 109, $1704-1711$. [CrossRef]

24. Jimenez, A. Tablas de Composición de Alimentos; Barcelona Novartis Consum Heal SA: Barcelona, Spain, 2002.

25. Mataix, J. Tablas de Composición de Alimentos Españoles; Granada Univ Granada: Granada, Spain, 2003.

26. Spanish Food Composition Database. Available online: https://www.bedca.net/bdpub/ (accessed on 22 November 2020).

27. FoodData Central; US Department of Agriculture, Agricultural Research Service: Washington, DC, USA, 2019.

28. Available online: https://fdc.nal.usda.gov/download-datasets.html (accessed on 22 November 2020).

29. Máiz, L.; Baranda, F.; Coll, R.; Prados, C.; Vendrell, M.; Escribano, A.; Gartner, S.; de Gracia, S.; Martínez, M.; Salcedo, A.; et al. Normativa del diagnóstico y el tratamiento de la afección respiratoria en la fibrosis quística. Arch. Bronconeumol. 2001, 37, 316-324. [CrossRef]

30. Gur, M.; Bar-Yoseph, R.; Diab, G.; Hanna, M.; Rozen, G.; Daud, F.; Keidar, Z.; Toukan, Y.; Masarweh, K.; Nir, V.; et al. Understanding the interplay between factors that influence bone mineral density in CF. Pediatr. Pulmonol. 2020, 55, $2667-2673$. [CrossRef] [PubMed]

31. Rikkonen, T.; Sirola, J.; Salovaara, K.; Tuppurainen, M.; Jurvelin, J.S.; Honkanen, R.; Kröger, H. Muscle Strength and Body Composition Are Clinical Indicators of Osteoporosis. Calcif. Tissue Int. 2012, 91, 131-138. [CrossRef] [PubMed]

32. Roca, J.; Sanchis, J.; Agusti-Vidal, A.; Segarra, F.; Navajas, D.; Rodriguez-Roisin, R.; Casan, P.; Sans, S. Spirometric reference values from a Mediterranean population. Bull. Eur. Physiopathol. Respir. 1986, 22, 217-224.

33. Gruet, M.; Troosters, T.; Verges, S. Peripheral muscle abnormalities in cystic fibrosis: Etiology, clinical implications and response to therapeutic interventions. J. Cyst. Fibros. 2017, 16, 538-552. [CrossRef]

34. Sheikh, S.; Zemel, B.S.; Stallings, V.A.; Rubenstein, R.C.; Kelly, A. Body Composition and Pulmonary Function in Cystic Fibrosis. Front. Pediatr. 2014, 2, 33. [CrossRef]

35. Hussey, J.; Gormley, J.; Leen, G.; Greally, P. Peripheral muscle strength in young males with cystic fibrosis. J. Cyst. Fibros. 2002, 1, 116-121. [CrossRef]

36. White, J.V.; Guenter, P.; Jensen, G.; Malone, A.; Schofield, M.; Academy Malnutrition Work Group; A.S.P.E.N. Malnutrition Task Force; the A.S.P.E.N. Board of Directors. Consensus Statement: Academy of Nutrition and Dietetics and American Society for Parenteral and Enteral Nutrition. J. Parenter. Enter. Nutr. 2012, 36, 275-283. [CrossRef]

37. Becker, P.; Carney, L.N.; Corkins, M.R.; Monczka, J.; Smith, E.; Smith, S.E.; Spear, B.A.; White, J.V.; Academy of Nutrition and Dietetics; American Society for Parenteral and Enteral Nutrition; et al. Consensus Statement of the Academy of Nutrition and Dietetics/American Society for Parenteral and Enteral Nutrition: Indicators Recommended for the Identification and Documentation of Pediatric Malnutrition (Undernutrition). Nutr. Clin. Pract. 2015, 30, 147-161. [CrossRef]

38. Norman, K.; Stobäus, N.; Gonzalez, M.C.; Schulzke, J.-D.; Pirlich, M. Hand grip strength: Outcome predictor and marker of nutritional status. Clin. Nutr. 2011, 30, 135-142. [CrossRef]

39. Ms, H.T.G.; McDonald, C.M.; Derrick, J.W.; Eggett, D.L.; Bellini, S.G. Evaluating Changes in Handgrip Strength in Children With Cystic Fibrosis: A Pilot Study. Nutr. Clin. Pr. 2018, 33, 261-267. [CrossRef]

40. Olveira, G.; Olveira, C.; Gaspar, I.; Porras, N.; Núñez, G.M.M.; Rubio-Martín, E.; Colomo, N.; Rojo-Martínez, G.; Soriguer, F. Fat-Free Mass Depletion and Inflammation in Patients with Bronchiectasis. J. Acad. Nutr. Diet. 2012, 112, 1999-2006. [CrossRef] [PubMed]

41. Radtke, T.; Puhan, M.; Hebestreit, H.; Kriemler, S. The 1-min sit-to-stand test-A simple functional capacity test in cystic fibrosis? J. Cyst. Fibros. 2015, 15, 223-226. [CrossRef] [PubMed]

42. Contreras-Bolívar, V.; Olveira, G.; Porras, N.; Acosta, E.; Rubio-Martín, E.; Tapia-Guerrero, M.J.; Abuin-Fernández, J. Osteopenia and Osteoporosis in Patients with Bronchiectasis: Association with Respiratory Parameters, Body Composition, Muscle Strength and Bone Remodeling Biomarkers. Sci. Rep. 2019, 9, 1-10. [CrossRef]

43. Olveira, G.; Olveira, C.; Doña, E.; Palenque, F.J.; Porras, N.; Dorado, A.; Godoy, A.M.; Rubio-Martínez, E.; Rojo-Martínez, G.; Martín-Valero, R. Oral supplement enriched in HMB combined with pulmonary rehabilitation improves body composition and health related quality of life in patients with bronchiectasis (Prospective, Randomised Study). Clin. Nutr. 2015, 35, 1015-1022. [CrossRef] [PubMed] 